\title{
Immunotoxicity of Penicillium Mycotoxins on Viability and Proliferation of Bovine Macrophage Cell Line (BOMACs)
}

\author{
Se-Young $\mathrm{Oh}^{*}{ }^{*}$, Herman J. Boermans ${ }^{2}$, H.V.L.N. Swamy ${ }^{3}$, Bhawani S. Sharma ${ }^{1}$ and \\ Niel A. Karrow ${ }^{1}$ \\ ${ }^{I}$ Department of Animal and Poultry Science (APS), Ontario Agriculture College (OAC), University of Guelph, Guelph, \\ ON, N1G 2W1, Canada \\ ${ }^{2}$ Department of Biomedical Science, Ontario Veterinary College (OVC), University of Guelph, Guelph, ON, N1G 2Wl, \\ Canada \\ ${ }^{3}$ Alltech Inc. Guelph, ON, N1G 4W1, Canada
}

\begin{abstract}
Penicillium mycotoxins are natural contaminants found in grains, crops, fruits, and fermented products, especially during post harvest as well as storage periods. Contamination by individual and combinations of these toxins is likely to compromise food quality and safety. In this study, the potential immunotoxicity of citrinin (CIT), ochratoxin A (OTA), patulin (PAT), mycophenolic acid (MPA) and penicillic acid (PA) was evaluated using a bovine macrophage cell line (BOMACs) by assessing their potential cytotoxicity and then their effects on cell proliferation. The BOMACs were exposed to a range of mycotoxin concentrations, and then to different mycotoxin combinations for 48 hrs. Some cytotoxicity was evident at concentrations greater than $2.4 \mu \mathrm{M}$ for PAT, and $160 \mu \mathrm{M}$ for PA, however, at the IC50 (concentration that inhibits $50 \%$ cell proliferation), no cytotoxicity was observed for either of these mycotoxins. The mycotoxin IC50s from most potent to least potent were $0.56 \mu \mathrm{M}$ (PAT), $12.88 \mu \mathrm{M}$ (OTA), $29.85 \mu \mathrm{M}$ (PA), and 91.20 $\mu \mathrm{M}$ (CIT). Concentrations of MPA greater than $80 \mu \mathrm{M}$ did not inhibit cell proliferation enough to calculate an IC50. Significant higher inhibition of cell proliferation was observed from the combinations of CIT+OTA, OTA+PAT, and OTA+PA compared to the effects of individual mycotoxins suggesting additive and in some cases synergistic activity between these paired mycotoxins.
\end{abstract}

Keywords: Bovine, Macrophages, Penicillium mycotoxins.

\section{INTRODUCTION}

Mycotoxins are metabolites of filamentous fungi that naturally contaminate a wide variety of crops, and therefore cereals and livestock feeds, worldwide [1,2]. The Food and Agriculture Organization of the United Nations (FAO) estimated that approximately $25 \%$ of the food and food stuffs in the world are compromised by mycotoxin contamination [3]. Economic losses from mycotoxin contamination occur due to reduced crop yield and value, and reduced livestock productivity and animal health from the consumption of contaminated feed [4]. Environmental conditions associated with high humidity and temperature favor fungal contamination of feed stuffs, and this can significantly affect the safety of both human and animal feed [5]. The effects of individual mycotoxins, such as carcinogenicity, teratogenicity, genotoxicity, nephrotoxicity as well as immunotoxicity have been studied, but their combinational effects have not been assessed [6-8]. One of the difficulties associated with characterizing the toxicity of mycotoxins is that contaminated feedstuffs may contain various combinations of mycotoxins produced by different fungal species [9]. For example,

\footnotetext{
*Address correspondence to this author at the Department of Animal and Poultry Science (APS), Ontario Agriculture College (OAC), University of Guelph, 50 Stone Road East, Building \#70, Guelph, ON, N1G 2W1, Canada; Tel: 1 (519) 824-4120, Ext. 58365; Fax: 1 (519) 836-9873;

E-mail: ohs@uoguelph.ca
}

Penicillium expansum produces citrinin (CIT), ochratoxin A (OTA), and patulin (PAT), while Aspergillus ochraceus produces OTA and PA [10-12]. Additionally, Fusarium mycotoxins are typically more abundant in corn silage immediately post-harvest, whereas Penicillium mycotoxin contamination increases during storage (Haladi, personal communication).

Among many fungal species, the Penicillium, Aspergillus, and Fusarium fungi are the most predominant species found in livestock feed such as corn silage [13-16]. Many studies have characterized the impact of oral exposure to Fusarium and Aspergillus mycotoxins on livestock species and examples of genotoxicity and immunotoxicity have been reported [15,17]. However, little is known about the impact of exposure to Penicillium mycotoxins, despite their potential to modulate immune function $[6,18,19]$. It is assumed that mycotoxins in general are detoxified by rumen microflora [20], since commensal microbes within ruminants have capacity to neutralize mycotoxins produced from Fusarium or Aspergillus mold before they enter the systemic circulation via the hepatic portal vein [21]. Many Penicillium mycotoxins on the other hand, are known to have antimicrobial properties, which could disrupt the normal function of these microbes, including their detoxification of Penicillium mycotoxins $[22,23]$. Therefore, Penicillium mycotoxin exposure may be especially relevant to the health of 
ruminant species, especially since they are frequently found in contaminated silage.

In this study, we evaluated the cytotoxicity and combined effect of exposure to CIT, OTA, PAT, mycophenolic acid (MPA), and penicillic acid (PA) on the proliferation of a bovine macrophage cell line (BOMACs). We hypothesized that Penicillium mycotoxins will alter the proliferation of BOMACs in a dose-dependent manner, and that certain combinations of these mycotoxins will additively and/or synergistically inhibit the cell proliferation.

\section{METHODS}

\section{Cell Preparation and Mycotoxin Exposure}

The BOMACs (provided by J.R. Stabel and T.J. Stabel, 1995) were cultured in RMPI 1640 supplemented with 2.0 $\mathrm{mM}$ L-glutamine, $10 \%$ heat inactivated fetal bovine serum (FBS), $100 \mathrm{unit} / \mathrm{ml}$ of penicillin, $100 \mu \mathrm{g} / \mathrm{ml}$ of streptomycin, $0.25 \mu \mathrm{g} / \mathrm{ml}$ of amphotericin B, and $25 \mathrm{mM}$ HEPES buffer (Invitrogen, ON, Canada) [24]. After reaching confluence, the BOMACs were dislodged with $0.05 \%$ trypsin-EDTA (Invitrogen, ON, Canada), seeded into 96-well flat bottom plates (10,000 cells per well), and incubated at $37^{\circ} \mathrm{C}$ with $5 \%$ $\mathrm{CO}_{2}$ for $1 \mathrm{hr}$. The BOMACs were then exposed to a range of concentrations of CIT, OTA, PAT, MPA, and PA (Sigma, ON, Canada, Table 1) dissolved in DMSO for $47 \mathrm{hrs}$ at $37^{\circ} \mathrm{C}$ with $5 \% \mathrm{CO}_{2}$. The ranges of exposure concentration were selected based on cited IC50s determined for bovine and porcine lymphocytes [6,19], and several preliminary trials using BOMACs that were used to optimize the toxic range of concentrations for each mycotoxin.

Table 1. Mycotoxin Concentrations Used for BOMAC Exposure Study

\begin{tabular}{|c|c|}
\hline Mycotoxins & Concentrations $(\mu \mathbf{M})$ \\
\hline \hline CIT & $2.5,5,10,20,30,40,60,80,160,320$ \\
\hline \multirow{2}{*}{ OTA } & $0.30,0.60,1.2,2.4,4.8,7.0,9.6$, \\
& $14,19.2,38.4$ \\
\hline \multirow{2}{*}{ PAT } & $\begin{array}{c}0.0038,0.0075,0.015,0.038,0.075,0.15, \\
0.2,0.3,0.4,0.5,0.6,1.2,2.4,4.8\end{array}$ \\
\hline MPA & $\begin{array}{c}0.05,0.10,0.2,0.4,0.6,0.8, \\
1.6,3.2,32,160,320\end{array}$ \\
\hline PA & $2.5,4,5,10,15,20,40,80,160,320$ \\
\hline
\end{tabular}

\section{Assessing Cytotoxicity of CIT, OTA, PAT, MPA, and PA to BOMACs}

After 47 hrs of mycotoxin exposure, another batch of BOMACs was seeded into 96-well plates $(50,000,37,500$, 25,000, 12,500, 0 cells per well) and incubated for $1 \mathrm{hr}$ at $37^{\circ} \mathrm{C}$ with $5 \% \mathrm{CO}_{2}$ - these cells were used as viable standards for the cytotoxicity assay. A parallel standard for dead cells was also prepared by incubating BOMACs in $70 \%$ methanol at room temperature for $1 \mathrm{hr}$ - these cells were stained with $0.1 \%$ trypan blue and viewed under a light microscope to confirm cell death. The standard for dead cells was prepared by seeding the dead cells into the 96-well plates already containing the standard for live cells such that the live cell proportion was equivalent to $100,75,50,25$, and $0 \%$. At 48 hrs post mycotoxin exposure, all plates including the standards were washed with PBS, and cytotoxicity was assessed using a commercially available cytotoxicity kit (Invitrogen, ON, Canada). The number of live cells was estimated using a 1420 Victor2 Multilabel Counter (Beckman Coulter, Inc. California) by measuring the fluorescence of calcein AM (excitation 494/emission $517 \mathrm{~nm}$ ), once it was hydrolyzed by intracellular esterases, and the number of dead cells was estimated by measuring the fluorescence of ethidium homodimer-1 (excitation 528/emission $617 \mathrm{~nm}$ ) bound to nucleic acids. When possible, the LC50 (concentration that kills $50 \%$ of cells) was calculated for each mycotoxin using the Graphpad Prism software (La Jolla, California, U.S.A.).

\section{Assessing the Inhibitory Effect of CIT, OTA, PAT, MPA, and PA on BOMAC Proliferation}

The BOMACs were exposed to the mycotoxins as described above, and after $47 \mathrm{hrs}$ of exposure, a standard for the proliferation assay was prepared by seeding another batch of BOMACS $(50,000,25,000,12,500,6,250,3,125$, $1,563,782,0$ per well) into the 96-well plates for $1 \mathrm{hr}$ of incubation at $37^{\circ} \mathrm{C}$ with $5 \% \quad \mathrm{CO}_{2}$. The media was then removed from all plates by blotting, and the plates were frozen for $24 \mathrm{hrs}$ at $-80^{\circ} \mathrm{C}$ prior to the proliferation assay. The number of cells was estimated using a commercially available proliferation kit (Invitrogen, ON, Canada) that uses CyQUANT® GR dye (excitation 494/emission $517 \mathrm{~nm}$ ) to label nucleic acids. The fluorescence intensity was measured with a 1420 Victor2 Multilabel Counter. The IC50 (concentration that inhibits $50 \%$ cell proliferation) for each mycotoxin was calculated using the Graphpad Prism software.

\section{Assessing the Combined Effects of Penicillium Mycotoxin on BOMAC Proliferation}

The IC25 for each mycotoxin was calculated using the Graphpad Prism software and is shown in the toxicity curves in Fig. (1). The BOMACs were then subjected to exposure by various combinations of CIT, OTA, PAT, MPA, and PA at their respective IC25s and to the individual mycotoxins (Table 2); cell proliferation was then assessed as described above.

Table 2. The LC50, IC50, and IC25 Various Penicillium Mycotoxins $(\mu \mathrm{M})$

\begin{tabular}{|c|c|c|c|c|c|}
\hline & CIT & OTA & PAT & MPA & PA \\
\hline \hline LC50 & N/A & N/A & 4.46 & N.A & 175.79 \\
\hline IC50 & 91.20 & 12.88 & 0.56 & N/A & 29.85 \\
\hline IC25 & 52.72 & 8.91 & 0.32 & 0.50 & 13.90 \\
\hline R-Square* & 0.945 & 0.981 & 0.841 & 0.871 & 0.987 \\
\hline
\end{tabular}

*R-square: the fitness of curve with the data points from Fig. (1B)

\section{Data Analysis}

All data are presented as percent cytotoxicity and percent cell proliferation, based on the combined results of three 


\section{A. \% Cell Death of BOMACs upon Mycotoxin Exposures}

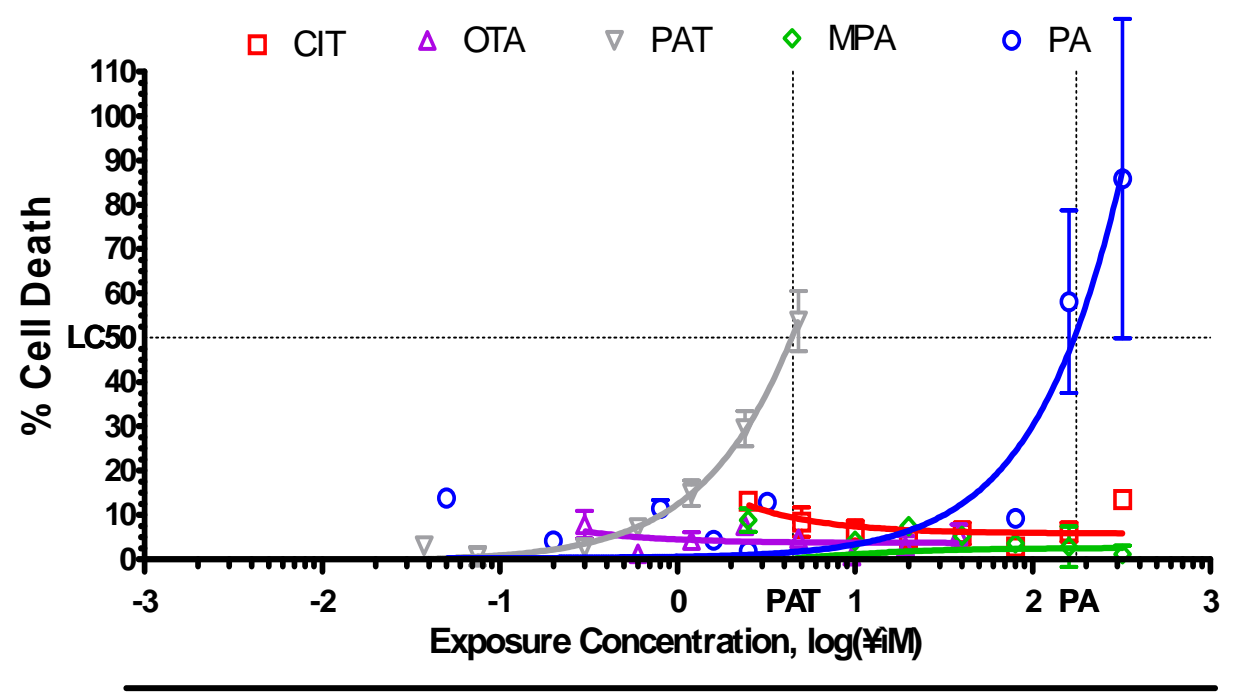

B. \% Proliferation of BOMACs upon Mycotoxin Exposures

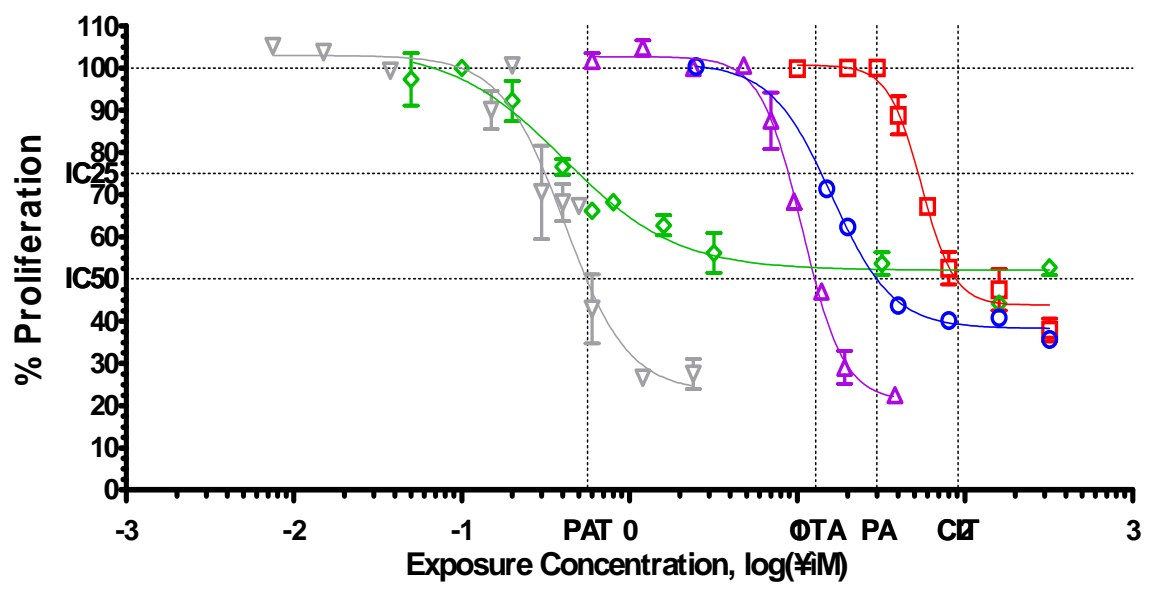

Fig. (1). A. Cytotoxicity and B. Proliferation of BOMACs following 48 hrs of Mycotoxin Exposure. CIT( $\square)$, OTA( ), PAT( $\nabla)$, and $\operatorname{MPA}(\diamond), \mathrm{PA}(\circ)$. LC50s (the concentraion that kills $50 \%$ of cells) are indicated in A; IC25s (The concentrations that inhibits $25 \%$ cell proliferation) and IC50s (The concentrations that inhibits 50\% cell proliferation) are indicated in B with dotted lines.

independent experiments. For the dose-response data, an ANOVA followed by Dunnett's test was used to test for statistical significance between the solvent controls and treatments (b), and a T-test was used to make comparisons between the control and solvent control (a). For the combined mycotoxins, an ANOVA followed by Tukey's test for comparisons was used to compare treatment groups (c) (Fig. 2). The concentration data were log transformed for the analysis, and significance was determined at a p-value $\leq 0.05$ using the Graphpad Prism software.

\section{RESULTS AND DISCUSSIONS}

\section{Cytotoxicity and Inhibition of the Cell Prolifreration due to Individual Mycotoxin Exposure}

Cytotoxicity was evident at concentrations greater than $2.4 \mu \mathrm{M}$ for PAT, and $160 \mu \mathrm{M}$ for PA; the LC50s for PAT and PA were estimated to be $4.46 \mu \mathrm{M}$ and $175.79 \mu \mathrm{M}$, respectively (Table 2 ). The cytotoxicity of PAT and PA may be due to their genotoxic effect on BOMACs. In support of this, Liu et al., (2003) concluded PAT as a potent clastogen with the ability to cause oxidative damage to DNA in hamster ovary cells and human peripheral blood lymphocytes, while CIT did not exhibit any significant evidence of such genotoxicity [8]. In the present study, CIT, OTA, and MPA did not induce any cytotoxicity within the concentration ranges tested (Fig. 1A). It is possible that higher concentrations of these mycotoxins would have induced sufficient cytotoxicity to estimate their respective LC50s, however, the concentration of DMSO at these higher concentrations would have also inhibit the proliferation of BOMACs, biasing the results of the proliferation assay (Data not shown).

In the context of cell proliferation, the mycotoxin IC50s calculated in this study occurred at concentrations where no overt cytotoxicity occurred, and their order of potency from highest to lowest was: $0.56 \mu \mathrm{M}(\mathrm{PAT})>12.88 \mu \mathrm{M}$ (OTA) > $29.85 \mu \mathrm{M}(\mathrm{PA})>91.20 \mu \mathrm{M}$ (CIT) (Table 2). When these IC50s were compared to IC50s determined from other stu- 
dies, it appears that BOMACs are less sensitive to CIT, OTA, and PA, but are more sensitive than porcine and bovine lymphocytes to PAT (Table 3). The exposure concentrations of some of the mycotoxins investigated and IC50s determined in this study, such as OTA, were higher than circulating concentrations reported from in vivo studies [25, 26]. However, there is the potential for their bioaccumulation in certain target tissues, such as kidney, intestine, and cutaenous fat $[27,28]$, as well as their synergistic and additive interaction among other mycotoxins within these tissues [29].

Table 3. Comparision of Mycotoxin IC50s for Cell Proliferation of Porcine and Bovine Lymphocytes $(\mu \mathbf{M})$

\begin{tabular}{|c|c|c|c|}
\hline & $\begin{array}{c}\text { Porcine } \\
\text { Lymphocyte [6] }\end{array}$ & $\begin{array}{c}\text { Bovine } \\
\text { Lymphocyte [19] }\end{array}$ & BOMACs \\
\hline \hline CIT & 38.00 & 44.27 & 91.20 \\
\hline OTA & 1.30 & 4.41 & 12.88 \\
\hline PAT & 1.20 & 3.63 & 0.56 \\
\hline PA & 18.00 & N/A & 29.85 \\
\hline
\end{tabular}

Based on the observations of this study, MPA was found to have little effect on BOMACs. Although MPA concentra- tions of $32 \mu \mathrm{M}$ and $320 \mu \mathrm{M}$ did inhibit cell proliferation, the response was not significantly different between these concentrations, and was not substantial enough to estimate an IC50 (Fig. 1B). The inhibitory mechanism of MPA on cell proliferation has been well studied. Mycophenolic acid and its commercial analogue, mycophenolate mofetil (MM), block the de-novo purine biosynthesis pathway, which is required for lymphocyte proliferation, by reducing cellular NF-kB levels [30]. While the proliferation of B- and T-lymphocytes relies heavily on the de novo pathway, BOMACs may equally utilize both de-novo and salvage pathways for their proliferation [31]. Furthermore, a more gradual reducetion in cell proliferation was observed at the lower MPA concentrations when compared to the other mycotoxins (Fig. 1B). These distinct characteristics may suggest why MPA and MM have been successfully used for treatment of allogenic transplantation as well as other immune-mediated diseases $[32,33]$.

\section{Combined Effect of Penicillium Mycotoxins on the Proliferation of BOMACs}

When the ten different combinations of mycotoxins were evaluated in the present study, three combinations signifycantly inhibited the proliferation of BOMACs when compared to the individual mycotoxins. These combinations included; CIT+OTA, OTA+PAT, and OTA+PA, (Fig. 2). Combinations of CIT, OTA, and PA were of interest because (a)

(c)

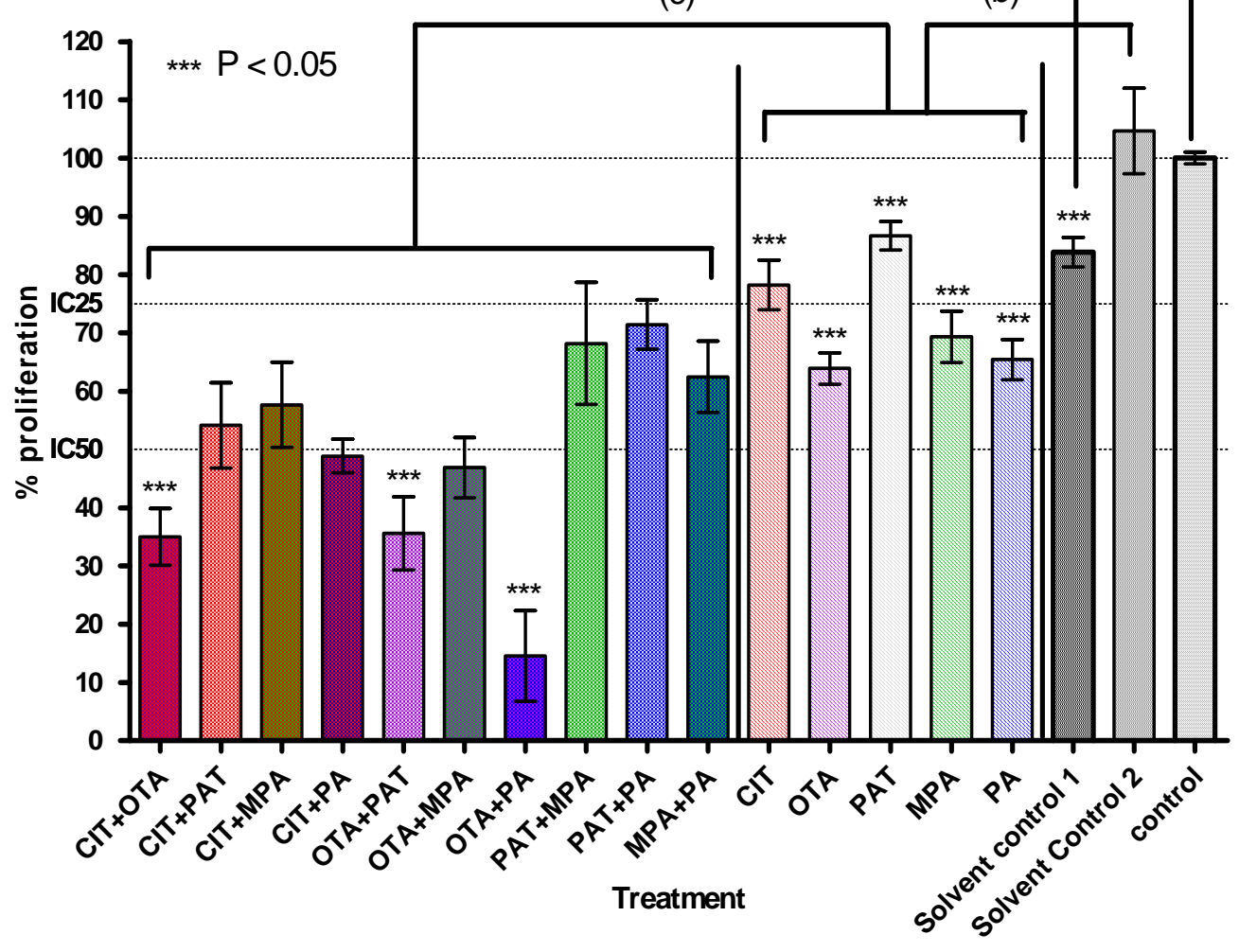

Fig. (2). The combined Effects of Mycotoxins on the Proliferation of BOMACs. Solvent control 1 is only for the combinations of CIT+OTA. Solvent control 2 is for all other combinations and individual mycotoxins. (a) control vs. solvent controls; (b) the solvent controls vs. individual treatments; (c) combined $v s$. individual treatments. 
these mycotoxins can be produced by Penicillium viridicatum, whereas Aspergillus ochraceus produces OTA and PA [10, 34]. Penicillium Expansum, which is commonly found in rotten apples, is also capable of producing CIT, PAT, and OTA $[11,12]$. The combination of CIT+OTA was previously demonstrated to increase chicken embryonic toxicity compared to CIT or OTA, alone [35]. Additionally, Sansing et al., (1976) reported that CIT+OTA and OTA+PA inhibited orotic acid incorporation into liver and kidney tissues, while this inhibitory effect was not observed from any of the individual mycotoxins [10]. Furthermore, the synergistic and additive interaction between CIT and OTA as well as OTA and PA on nephrotoxicity, hepatotoxicity and teratogenicity has been well addressed in other studies [36, 37]. In the present study, the proliferation of BOMACs was shown to be inhibited in an additive manner with the combinations of CIT+OTA and OTA+PAT, while the synergistic activity was observed from the combination of OTA+PA (Fig. 2).

\section{CONCLUSIONS}

The inhibitory effect of the following Penicillium mycotoxins, CIT, OTA, PAT, MPA, and PA, as well as their combinations, on the cytotoxicity and proliferation of BOMACs was evaluated in this study. All mycotoxins except MPA inhibited cell proliferation by at least $50 \%$ with the evidence of cytotoxicity from PAT and PA for the concentration ranges used in this study. Most of these toxic concentrations determined in the study are higher than circulating concentrations from in vivo studies, yet the continuous consumption of feed contaminated with these toxins may lead to their accumulation in host tissues potentially increasing their bioavailability to the host immune cells. Of greater concern, however, was the additive or synergistic effects of various combinations of mycotoxins including; CIT+OTA, OTA+ PAT, and OTA+PA. Since these mycotoxins can be naturally found in these combinations, their effects on the immune system warrant further investigation.

\section{CONFLICT OF INTEREST}

None declared.

\section{ACKNOWLEDGEMENT}

We give special thanks to Alltech Inc. and OMAFRA (Ontario Ministry of Agriculture, Food and Rural Affairs) for financially supporting this study. We also would like to give appreciation to Qiumei You for her technical support.

\section{ABBREVIATION}

$\begin{array}{ll}\text { CIT } & =\text { Citrinin } \\ \text { OTA } & =\text { Ochratoxin A } \\ \text { PAT } & =\text { Patulin } \\ \text { MPA } & =\text { Mycophenolic acid } \\ \text { PA } & =\text { Penicillic acid } \\ \text { MM } & =\text { Mycophenolate mofetil }\end{array}$

BOMACs $=$ Bovine macrophage cell line

IC50 $=$ Concentration that inhibits $50 \%$ of cell proliferation

IC25 $=$ Concentration that inhibit $25 \%$ of cell proliferation

LC50 $=$ Concentration that kills $50 \%$ of cells

\section{REFERENCES}

[1] Tanaka T, Hasegawa A, Yamamoto S, Lee US, Sugiura Y, Ueno Y. Worldwide contamination of cereals by the Fusarium mycotoxins nivalenol, deoxynivalenol, and zearalenone. 1. Survey of 19 countries. J Agric Food Chem 1988 Sep; 36(5): 979-83.

[2] Placinta CM, D'Mello JPF, Macdonald AMC. A review of worldwide contamination of cereal grainsand animal feed with Fusarium mycotoxins. Animal Feed Sci \& Tech 1999; 78: 21-37.

[3] Park DL, Njapau H, Boutrif E. Minimizing risks posed by mycotoxins utilizing the HACCP concept [Internet]. 2009 Nov 17 [cited 2009 Nov 17]; Available from: http://www.fao.org/docrep/x2100t/x2100t08.htm

[4] Schmale III DG, Munkvold GP. Mycotoxins in Crops: A Threat to Human and Domestic Animal Health [homepage on Internet]. 2009 Nov 16 [cited 2009 Nov 16]; Available from: http://www.apsnet.org/education/IntroPlantPath/Topics/mycotoxins /Pages/impact.html

[5] Miraglia M, Marvin HJP, Kleter GA, Battilani P, Brera C, Coni E, et al. Climate change and food safety: An emerging issue with special focus on Europe. Food and Chemical Toxicology. 2009 May; 47(5): 1009-21.

[6] Keblys M, Bernhoft A, Höfer CC, Morrison E, Larsen HJS Flåøyen A. The effects of the Penicillium mycotoxins citrinin, cyclopiazonic acid, ochratoxin A, patulin, penicillic acid, and roquefortine $\mathrm{C}$ on in vitro proliferation of porcine lymphocytes. Mycopathologia. 2004 Oct; 158(3): 317-24.

[7] Ciegler A, Vesonder RF, Jackson LK. Production and Biological Activity of Patulin and Citrininfrom Penicillium expansum. Appl Environ Microbiol. 1977 Apr; 33(4): 1004-6.

[8] Liu B-H, Yu F-Y, Wu T-S, Li S-Y, Su M-C, Wang M-C, et al. Evaluation of genotoxic risk and oxidative DNA damage in mammalian cells exposed to mycotoxins, patulin and citrinin. Toxicol Appl Pharmacol 2003 Sep 15; 191(3): 255-63.

[9] Mansfield MA, Jones AD, Kuldau GA. Contamination of Fresh and Ensiled Maize by Multiple Penicillium Mycotoxins. Phytopathology 2008 Mar; 98(3): 330-6.

[10] Sansing GA, Lillehoj EB, Detroy RW, Miller MA. Synergistic toxic effects of citrinin, ochratoxin $\mathrm{A}$ and penicillic acid in mice. Toxicon 1976; 14(3): 213-20.

[11] Andersen B, Smedsgaard J, Frisvad JC. Penicillium expansum: Consistent Production of Patulin, Chaetoglobosins, and Other Secondary Metabolites in Culture and Their Natural Occurrence in Fruit Products. J Agric Food Chem 2004; 52(8): 2421-8.

[12] Martins ML, Gimeno A, Martins HM, Bernardod F. Co-occurrence of patulin and citrinin in Portuguese apples with rotten spots. Food Addit Contam 2002 Jun; 19(6): 568-74.

[13] Pozzi CR, Corrêa B, Gambale W, Paula CR, ChaconRechea NO, Meirellesa MCA. Postharvest and stored corn in Brazil: mycoflora interaction, abiotic factors and mycotoxin occurrence. Food Addit Contam 1995 Jun; 12(3): 313-9.

[14] Dalcero A, Magnoli C, Chiacchiera S, Palacios G, Reynoso M. Mycoflora and incidence of aflatoxin B1, zearalenone and deoxynivalenol in poultry feeds in Argentina. Mycopathologia 1997; 137(3): 179-84.

[15] Pereyra CM, Alonso VA, Rosa CAR, Chiacchiera SM, Dalcero AM, Cavaglieri LR. Gliotoxin natural incidence and toxigenicity of Aspergillus fumigates isolated from corn silage and ready dairy cattle feed. World Mycotoxin J 2008 Nov; 1(4): 457-62.

[16] Amiri A, Bompeix G. Diversity and population dynamics of Penicillium spp. on apples in pre- and postharvest environments: consequences for decay development. Plant Pathology 2005 Feb; 54(1): 74-81.

[17] Visconti A, Minervini F, Lucivero G, Gambatesa V. Cytotoxic and immunototoxic effects of Fusarium mycotoxins a rapid colorimetric bioassay. Mycopathologia 1991 Mar; 113(3): 181-6. 
[18] Richetti A, Cavallaro A, Ainis T, Fimiani V. Effect of some mycotoxins on superoxide anion production of isolated human neutrophils and in whole blood. Immunopharmacol Immunotoxicol 2003 Aug; 25(3): 441-9.

[19] Stec J, Rachubik J, Szczotka M, and Kuzmak J. Effects of Penicillium Mycotoxins: ctrinin, ochratoxin A, and patulin on in vitro proliferation of bovine lymphocytes. Bulletin of the Vet. Insti in Pulaway 2008; 52: 163-67.

[20] Kiessling K-H, Pettersson H, Sandholm K, Olsen M. Metabolism of Aflatoxin, Ochratoxin, Zearalenone, and Three Trichothecenes by Intact Rumen Fluid, Rumen Protozoa, and Rumen Bacteria. Appl Environ Microbiol 1984 May; 47(5): 1070-73.

[21] Swanson SP, Nicoletti J, Rood HD Jr, Buck WB, Cote LM, Yoshizawa TM. Metabolism of Three Trichothecene Mycotoxins, T-2 toxin, Deacetoxyscirpenol and Deoxynivalenol, by Bovine Rumen Microorganisms. J Chromatogr 1987 Mar; 414(2): 335-42.

[22] Dzidic A, Meyer HH, Bauer J, Pfaffl MW. Long-term effects of mycophenolic acid on the immunoglobulin and inflammatory marker-gene expression in sheep white blood cells. Mycotoxin Res 2010; 26: 235-40.

[23] Bennett JW, Klich M. Mycotoxins. Clin Micro Rev 2003; 16: 497516.

[24] Stabel JR, Stabel TJ. Immortalization and characterization of bovine peritoneal macrophages transfected with SV40 plasmid DNA. Vet Immunol Immunopathol. 1995 Apr;45(3-4):211-20.

[25] Hohler D, Sudekum KH, Wolffram S, Frohlich AA, Marquardt RR. Metabolism and excretion of ochratoxin A fed to sheep. J Anim Sci 1999; 77: 1217-23.

[26] Blank R, Rolfs JP, Südekum KH, Frohlich AA, Marquardt RR, Wolffram S. Effects of chronic ingestion of ochratoxin A on blood levels and excretion of the mycotoxin in sheep. J Agric Food Chem. 2003 Nov 5; 51(23): 6899-905.

[27] Prelusky DB, Hamilton RMG, Trenholm HL, Miller JD. Tissue distribution and excretion of radioactivity following administration of ${ }^{14} \mathrm{C}$-labeled deoxynivalenol to White Leghorn hens. Fundam Appl Toxicol 1986; 7: 635-45.
[28] Galtier P, Alvinerie M, Charpenteau JL. The pharmacokinetic profiles of ochratoxin $\mathrm{A}$ in pigs, rabbits and chickens Food \& Cosme Tox 1981; 19: 735-8.

[29] Sansing GA, Lillehoj EB, Detroy RW, Miller MA. Synergistic Toxic Effects of Citrinin, Ochratoxin A and Penicillic acid in Mice. Toxicon 1976; 14: 213-20.

[30] Hauser IA, Johnson DR, Thévenod F, Goppelt-Strübe M. Effect of mycophenolic acid on TNF- induced expression of cell adhesion molecules in human venous endothelial cells In vitro. $\mathrm{Br} \mathrm{J}$ Pharmaol 1997 Dec; 122(7): 1315-22.

[31] Duncan MD, Wilkes DS. Transplant-related Immunosuppression: A Review of Immunosuppression and Pulmonary Infections. Proc Am Thorac Soc 2005; 2(5): 449-55.

[32] Pérez-Simón JA, Martino R, Caballero D, Valcarcel D, Rebollo N Cámara R de la, et al. Reduced-Intensity Conditioning Allogeneic Transplantation from Unrelated Donors: Evaluation of Mycophenolate Mofetil Plus Cyclosporin A as Graft-versus-Host Disease Prophylaxis. Bio of Blood \& Marrow Transplant 2008 Jun; 14(6): 664-71.

[33] Chaudhry V, Cornblath DR, Griffin JW, O’Brien R, Drachman DB. Mycophenolate mofetil: A safe and promising immunosuppressant in neuromuscular diseases. Neurology. 2001 Jan; 58(1): 94-6.

[34] Bacon CW, Sweeney JG, Robbins JD, Burdick D. Production of Penicillic acid and Ochratoxin A on Poultry Feed by Aspergillus ochraceus: Temperature and Moisture Requirement. Appl Environ Microbiol. 1973 Aug; 26(2): 155-60.

[35] Veselá D, Vesely D, Jelínek R. Toxic Effects of Ochratoxin A and Citrinin, Alone and in Combination, on Chicken Embryos. Appl Environ Microbiol 1983 Jan; 45(1): 91-3.

[36] Shepherd EC, Phillips TD, Joiner GN, Kubena LF, Heidelbaugh ND. Ochratoxin A and Penicillic acid interaction in mice. J of Envi Sci \& Health, Part B 1981; 16(5): 557-73.

[37] Speijers GJA, Speijers MHM. Combined toxic effects of mycotoxins. Toxlet 2004 Oct;153(1):91-8. 